\title{
Three Cases of Intravascular Thrombosis Occurring in Patients Receiving Oral Contraceptives
}

\author{
N. C. NEVIN,* M.D., B.SC. ; P. C. ELMES, † M.D., B.SC., M.R.C.P. ; J. A. WEAVER, $\ddagger$ M.D., M.R.C.P.
}

Brit. med. F., 1965, 1, 1586-1589

A possible relationship between thrombosis and oral contraceptives was first suspected in 1961, when fatal pulmonary embolism occurred in two young Californian women who had been receiving Enavid (F. Amer. med. Ass., 1963). In England a case report (Jordan, 1961) and a leading article (Brit. med. f., 1962) further directed attention to this association. Statistical evidence, however, has been regarded as failing to substantiate a causal relationship between oral contraceptive drugs and thrombotic disease (Chicago Conference, 1962 ; Mills, 1964).

Laboratory investigations into the possible changes in the coagulation balance which might significantly add to the risk of thrombosis have yielded conflicting results. Phillips et al. (1961) studied the effects of exogenous steroids on the clotting mechanism of human subjects. Their results indicate that 19-nor-steroid compounds produce a significant rise in profibrinolysin and fibrinolysin levels and a less marked increase in antifibrinolysin. Recently Egeberg and Owren (1963) reported that norethynodrel in recommended contraceptive dosage produced an increased coagulability of the blood as evidenced by shortened plasma cephalin time, greatly increased antihaemophilic A factor, and slight increase in proconvertin activity'. In addition, an increase in fibrinogen concentration was noted by Brakman and Astrup (1964). On the other hand, Sobrero et al. (1963) were unable to demonstrate any alteration in coagulation factors.

Although the pathogenetic relation between 19-nor-steroid compounds and thrombosis has not been clearly defined, increasing reports of thrombosis in patients receiving this medication are of grave concern (Gaylis and Kramer, 1962 ; Lorentz, 1962 ; McIntyre et al., 1962 ; Richman, 1962 ; Staddon, 1962 ; McWilliam et al., 1963 ; Minogue et al., 1963 ; Reed and Coon, 1963 ; Cohen and Sajid, 1964 ; Schatz et al., 1964 ; StewartWallace, 1964 ; Zilkha, 1964 ; Baines, 1965 ; Hartveit, 1965 ; Leather, 1965).

We therefore wish to record the case histories of three patients in whom intravascular thrombosis occurred while on oral contraceptive drugs.

\section{Case 1}

A 35-year-old married woman was admitted to hospital in a semicomatose state on 30 Novemher 1964. Five days prior to admission she had had a mild pharyngitis which was treated by her family physician with aspirin. At $8 \mathrm{p} . \mathrm{m}$. on the day of admission she felt cold, and one hour later became restless and confused. She was unable to move either her right arm or leg. Preceding headache, visual disturbance, or convulsive movements were not present. There was no history of rheumatic fever, arthritis, congestive cardiac failure, varicosities, phlebitis, pneumonia, drug reactions, trauma, or any other local or systemic disease associated with thromtosis.

Physical examination showed a well-nourished woman who, although drowsy, responded to simple commands. Speech was slurred. The right pupil was slightly larger than the left, but both reacted to light and on accommodation. There was upper-motorneurone weakness of the right face. She had a right hemiplegia. There was marked tenderness over the left common carotid.artery. Examination showed that the heart, chest, and abdomen were within

* Medical Registrar, Royal Victoria Hospital, Belfast.

$t$ Lecturer in Therapeutics, Queen's University of Belfast.

‡ Physician to Medical Out-patients, Royal Victoria Hospital, Belfast. normal limits. The temperature was $100^{\circ} \mathrm{F}$. $\left(37.8^{\circ} \mathrm{C}\right.$.), pulse $90 /$ minute, and blood-pressure $160 / 100 \mathrm{~mm}$. Hg. Chest $x$-ray examination showed no lesion in the lung fields and the cardiac shadow was within normal limits.

Laboratory studies included a haemoglobin of 10.9 g. $/ 100 \mathrm{ml}$. and a white-cell count of $18,100 /$ c.mm. The erythrocyte sedimentation rate was $45 \mathrm{~mm} . / 1$ hour. Urinalysis was normal. Total fatty acids were $18.0 \mathrm{mEq} /$ litre (upper limit of normal for this laboratory in premenopausal women, $14.8 \mathrm{mEq} / \mathrm{l}$.) and serum cholesterol was $259 \mathrm{mg} . / 100 \mathrm{ml}$. (modification of Zlatkis and Zak method: normal for premenopausal women, $217+34 \mathrm{mg}$.). The alpha/betalipoprotein ratio was 0.5 . Total plasma proteins, $7.5 \mathrm{~g} . / 100 \mathrm{ml}$. ; the albumin ( $3.38 \mathrm{~g} . / 100 \mathrm{ml}$.) was reduced, and electrophoresis showed a peak in the position of $\alpha_{2}$-globulin.

The next day a left carotid angiogram showed complete occlusion of the internal carotid artery at its origin. Immediate exploration af the left common carotid artery was undertaken by Mr. A. Taylor. The origin of the internal carotid artery was occluded with recent thrombus. The thrombus and the terminal portion of the left common carotid artery, together with the origin of the left internal and external carotid arteries, were removed. After the operation the patient's level of consciousness gradually deteriorated and she died the next morning.

At necropsy pathological lesions were confined to the brain and the cerebral arteries. In the brain there was an extensive recent infarct of the left cerebral hemisphere associated with oedema and uncal herniation. The arch of aorta, carotid, and vertebral arteries were removed in toto and injected with Micropaque (Figs. 1 and 2.) Thrombosis of the left common carotid artery proximal to the resection extended to within $1 \mathrm{~cm}$. of its origin, and thrombosis of the left internal

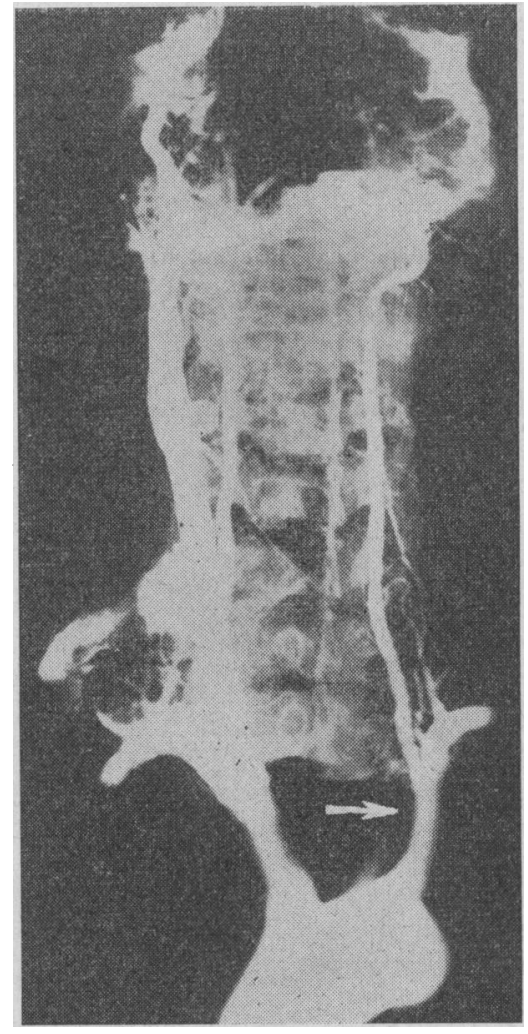

Fig. 1.-Case 1. Post-mortem injection with Micropaque of arch of aorta showing occlusion of left carotid system. carotid artery distal to

the resection extended into the left middle cerebral and the left anterior cerebral arteries. Histologically the carotid arteries showed no atheroma, but throughout the muscle coats of the left common carotid artery there were polymorphonuclear leucocytes. However, the tonsils, the pharynx, and the adjacent cervical lymph nodes did not show any acute inflammation. The polymorphonuclear leucocytes in the vessel wall were possibly due to the carotid angiogram.

The patient had five children, the youngest of whom was $1 \frac{1}{2}$ years old. Her pregnancies had been normal and were uncomplicated by 
toxaemia, haemorrhage, or thrombophlebitis. During the previous year she had been taking, for oral contraceptive purposes, Anovlar (norethisterone and ethinyloestradiol) on a cyclic regime of a 20-day course of one tablet daily, starting on the fifth day after the menstrual cycle.

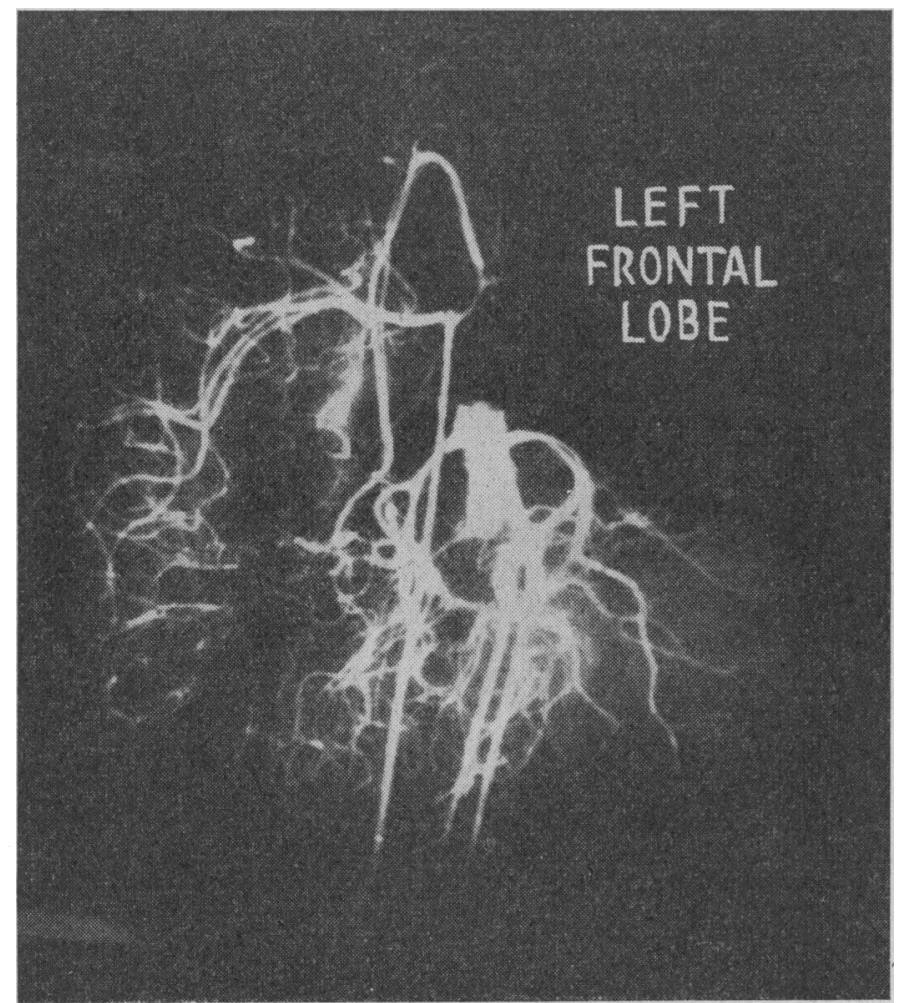

FIG. 2.-Case 1. Micropaque injection showing cerebral circulation with occlusion of left anterior and middle cerebral arteries.

\section{Case 2}

A 22-year-old married woman developed an influenza-like illness in May 1964. Her initial symptoms were general unwellness associated with a rise in temperature to $100^{\circ} \mathrm{F}$. $\left(37.8^{\circ} \mathrm{C}\right.$.). For the first three days of her illness she had few appreciable chest symptoms, but the third day a persistent cough had developed. Over the next few days she had pleural pain along the left lower ribs. The cough became associated with a tenacious red sputum, and at this stage she was confined to bed. Her family physician treated her with ampicillin, but as her condition failed to improve she was admitted to hospital on the tenth day of her illness.

On admission she appeared gravely ill, extremely dyspnoeic, and cyanosed. The temperature was $103^{\circ} \mathrm{F}$. $\left(39.4^{\circ} \mathrm{C}.\right)$, pulse rate $110 /$ minute, and respiration rate $35 /$ minute. Examination of the chest revealed dullness and diminished air entry at the left base. There was no localized tenderness in the thighs or the calves; Homan's sign was negative. The erythrocyte sedimentation rate was $30 \mathrm{~mm} . / 1$ hour, haemoglobin $11.3 \mathrm{~g} . / 100 \mathrm{ml}$., and white-cell count $8,600 /$ c.mm. Sputum was sent for culture and the patient was started on crystalline penicillin, one million units three-hourly. By the third day of this treatment her condition had improved slightly. She was less dyspnoeic, but the severe cough and haemoptysis continued. A chest $x$-ray examination showed consolidation in the left lower lobe with possibly fluid in the costophrenic angle. Her condition continued to show further improvement, but on several occasions a spike in her temperature occurred to 101 and $102^{\circ} \mathrm{F}$. (38.3 and $38.9^{\circ} \mathrm{C}$.).

By the seventh hospital day it was apparent she was deteriorating. Jugular venous pressure was elevated and the pulmonary second sound was accentuated. At the right base there was slight dullness with diminished air entry. A chest $x$-ray film showed slight resolution of the consolidation in the left lower lobe. The right lung field was regarded as clear. Twenty-four hours later a further chest $x$-ray film showed a small area of consolidation in the right lower lobe (Fig. 3). Other findings at this stage were that the haemoglobin had fallen to $9.9 \mathrm{~g} . / 100 \mathrm{ml}$. and the white-cell count was $7,900 / \mathrm{c} . \mathrm{mm}$. Repeated sputum cultures were negative for pathogens. Serum lactic dehydrogenase was on consecutive days 397 and 425 units (normal upper limit for this laboratory is 380 Steinberg units). An electrocardiogram showed a small primary $R$ wave in leads V1 and $\mathrm{T}$-wave inversion V1 and V2.

It was decided to start the patient on anticoagulant therapy on the assumption that the chest lesions might represent pulmonary embolic disease, and heparin 10,000 units subcutaneously was given sixhourly. From this point onwards she began to improve slowly. On 21 June, 10 days after development of the lesions on the right side of the chest, she complained of pain in the calf and behind the knee in the left leg. On examination there was a half-inch $(1.3-\mathrm{cm}$.) swelling of the mid-calf of the left leg with tenderness in the popliteal fossa ; Homan's sign was positive. Heparin therapy was continued with the addition of oral warfarin sodium.

On 2 July a pulmonary angiogram was done under local anaesthesia (Dr. E. M. McIlrath). The technique used was to insert catheters bilaterally in the antecubital fossae and to advance the tip

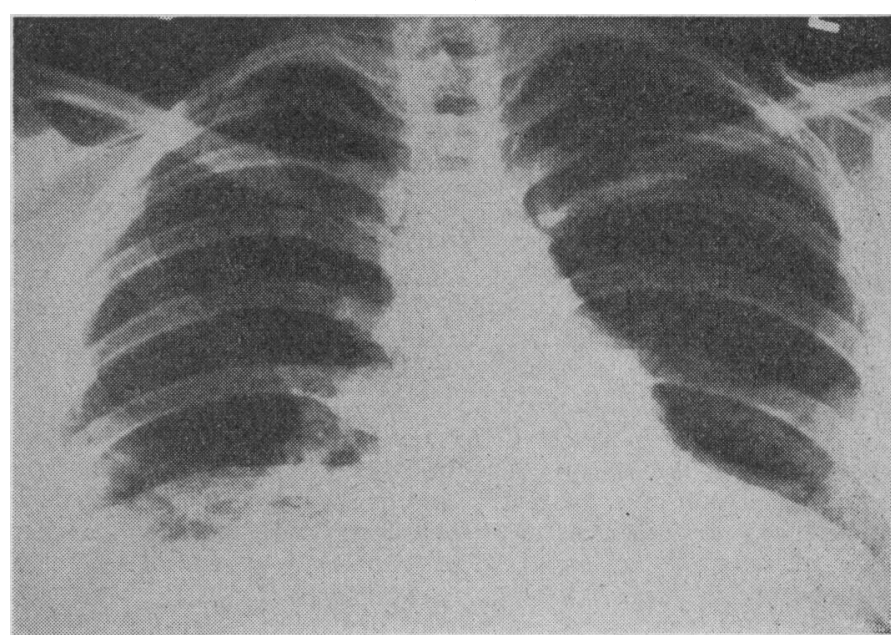

Fig. 3.-Case 2. Chest $x$-ray film. Bilateral pulmonary emboli.

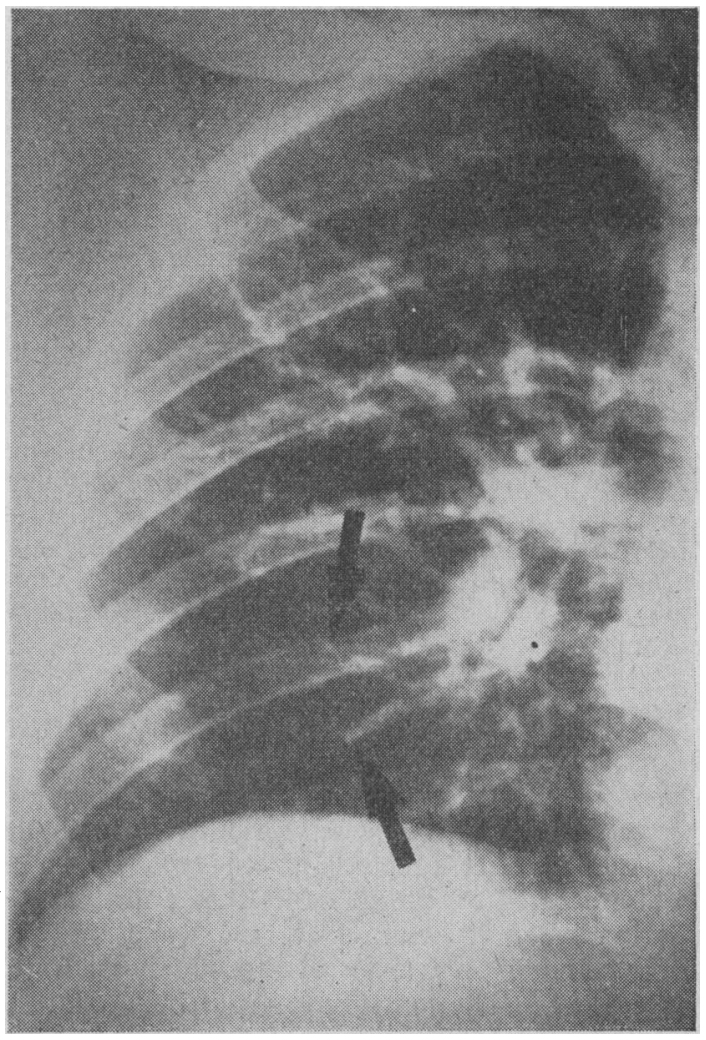

Fig. 4.-Case 2. Pulmonary angiogram (right lung field) showing avascular area at right base with occlusion of two arteries (arrows). 
of these towards the thoracic inlet (about 5 to 6 in. $; 12.5$ to $15 \mathrm{~cm}$.). Injection with $60 \mathrm{ml}$. of $65 \%$ Hypaque was made and 18 films at two-second intervals were taken. The films showed that the main pulmonary artery was large. The main left and right pulmonary arteries were normal. There was blockage of two mid-zone arteries on the right, with good peripheral circulation above the avascular area (Fig. 4). Two (probably three) arteries in the left mid-zone were also occluded. Spirometry studies showed that vital capacity was reduced, being 2.651 . ( $76 \%$ of predicted normal). The singlebreath carbon monoxide diffusing capacity D'Lco was $13 \mathrm{ml}$. $\mathrm{CO} / \mathrm{mm} . \mathrm{Hg} / \mathrm{min}$. ( $53.5 \%$ of predicted normal).

The patient had had two normal pregnancies uncomplicated by any disease and certainly none concerning embolic disease. After the birth of the last child, 18 months prior to this illness, she had started (for contraceptive purposes) on Conovid (norethynodrel and mestranol) on a cyclic regime of a 20-day course of 5 -mg. tablets starting on the fifth day after the menstrual cycle. She had continued to take Conovid throughout the first few days of her illness, but had come to the end of a 20-day cycle on the fourth day of her illness. She was continued on warfarin until November 1964. Her further course was uncomplicated.

\section{Case 3}

A 28-year-old married woman returned from Canada to the United Kingdom and for the first few days after the air flight felt excessively tired and unwell. About a week later she awoke one morning with an aching discomfort in the region of the left shoulder, made worse on deep breathing. During the course of that morning she coughed up fresh unclotted blood. She had been seen by her family physician and confined to bed. Temperature had fluctuated in the region of $100^{\circ} \mathrm{F}$. $\left(37.8^{\circ} \mathrm{C}\right.$.).

On admission to hospital she was not in any distress. Bloodpressure was $120 / 80 \mathrm{~mm} . \mathrm{Hg}$ and the cardiovascular system was normal. Diminished air entry was noticed at the left lung base. There was no tenderness in the calves or thighs and Homan's sign was negative. $X$-ray examination of the chest showed a small area of collapse in the left lower zone with slight elevation of the left dome of the diaphragm. Treatment had already been started by her family physician with ampicillin, and this was continued. Despite the absence of positive signs in the legs, she complained of a cramp-like feeling in the right lower calf, and on the second and third days after admission some tenderness developed at 2-3 in. (5-7.5 cm.) above the right Achilles tendon, and Homan's sign became positive. At this stage heparin 15,000 units intravenously every eight hours was begun and her further recovery was uneventful. Serum lactic dehydrogenase was normal at 230 units.

An intravenous pulmonary angiogram was carried out on 18 August. Compared with Case 2, less accurate visualization of the pulmonary arterial tree was obtained, but an area of blockage in the left lower lobe was thought to be present. Pulmonary function studies showed a diffusion defect. Vital capacity and subdivision of lung volume and F.E.V.1 were normal. The single-breath carbon monoxide diffusing capacity D'Lco was $15.8 \mathrm{ml}$. CO/mm. $\mathrm{Hg} / \mathrm{min}$. ( $64 \%$ of predicted normal).

The patient returned to Canada while still taking warfarin sodium with instructions to continue this therapy for three to four months.

The patient had three children, aged 7,5 , and 3 years. One month prior to the present illness she had started on Enavid (northethynodrel and mestranol), taking one tablet a day for a cycle of 20 days. She had stopped her first course of Enavid two days before the first symptoms.

\section{Discussion}

The possible association of thromboembolic disease with oral contraceptives has to be considered seriously in the light of the increasing number of case reports. Doubts that such a relationship exists are based on the concepts that pulmonary embolic disease is increasing (Morrell et al., 1963) and that thrombophlebitis is common in women of reproductive age (Chicago Conference, 1962). The controversy concerning oral contraceptives and thrombophlebitis, it has been claimed, has merely drawn attention to the true situation among healthy women. The Chicago Conference (1962) based its conclusions on a comparison of the morbidity rates of thrombophlebitis in the general population and in oral contraceptive users. With the use of figures from various sources (Saskatchewan Hospital Services Plan, Health Insurance Plan of New York) it was deduced that thrombophlebitis occurred in the general population at approximately a rate of one case per 1,000 of population per year. The Food and Drugs Administration Report (1963) was unwilling to regard this as a reliable criterion, as the morbidity of thrombophlebitis has many uncertainties, such as the variation in reporting, diagnostic acumen, geographic differences in occurrence, and other factors. The committee considered that mortality data might provide more dependable evidence. However, they did not find any significant difference between thromboembolic deaths in Enavid users and in the general population (12.1 deaths per million and 7.9 deaths per million respectively), but possible hazards were observed in women in the over-35 age group (18.3 deaths per million in Enavid users as compared with 7.9 deaths per million in the general population).

We have felt it justifiable to report these three cases as they had the common manifestation of intravascular thrombosis occurring in young healthy women while receiving oral contraceptive therapy. A review of the literature discloses that most case reports have been concerned with the development of thrombophlebitis and pulmonary embolism. However, there has been occasional reference to spontaneous arterial thrombosis in young women on oral contraceptive therapy (Brit. med. $\mathcal{F}$., 1962 ; Reed and Coon, 1963 ; Schatz et al., 1964 ; Hartveit, 1965). Recently attention has been drawn to the possibility that cerebrovascular disorders in young women may be related to this form of therapy (Stewart-Wallace, 1964 ; Zilkha, 1964 ; Baines, 1965).

Case 1 would appear to be an adequately documented occurrence of thrombosis of the internal carotid artery in a healthy woman while on Anovlar. Clinical investigation disclosed some alteration in the lipid constitution; while the cholesterol was normal there was an elevation in the total fatty acids. Necropsy examination did not show any atheromatous disease in the carotid arterial wall. At necropsy there was no evidence of local or systemic diseases associated with thrombosis.

It is, of course, true that young people may develop carotid artery thrombosis. In the accumulated literature Humphrey and Newton (1960) reviewed 124 cases in patients under the age of 40 . In approximately $50 \%$ of such cases precipitating factors such as trauma, inflammatory diseases, emboli, blood dyscrasias, and arteritic lesions were present. Similarly, other studies indicate the rarity of carotid artery occlusion in young subjects. Of the 107 patients with spontaneous carotid artery thrombosis reported by Johnson and Earl Walker (1951) only eight women were under 40 years ; whilst in 258 cases of complete or partial carotid artery occlusion reviewed by Gurdjian et al. (1960) seven were under 40 years. The literature describes three cases of carotid artery thrombosis occurring in post-partum patients, suggesting an association of hormonal effects on blood coagulation (Lemmen et al., 1958 ; Hutchinson and Yates, 1960 ; Humphrey and Newton, 1960).

Both Cases 2 and 3 also occurred in healthy women. There was no significant finding in the past histories or clinical examination to suggest a liability to thromboembolic disease. Case 2 was initially considered as suffering from pneumonia, but the subsequent clinical course did not support this diagnosis, and furthermore the pulmonary angiogram conclusively demonstrated arterial occlusion at the right lung base and probably similar lesions in the left basal zones.

A further aspect of Cases 2 and 3 is the delayed development of the signs of phlebothrombosis in the lower limbs. Clinical evidence of a clot in the leg veins occurred after three weeks' illness in Case 2, and after five to six days in Case 3. Stevens (1961) has emphasized the occurrence of the late appearance of leg symptoms in pulmonary embolism. Aid to the diagnosis 
of pulmonary embolism in Cases 2 and 3 was obtained by pulmonary angiography, using an intravenous route which in acutely ill patients is better tolerated than introduction of a catheter into the right ventricle (Williams et al., 1963). The elevated serum lactic dehydrogenase supported the diagnosis of pulmonary embolus in Case 2 but was unhelpful in Case 3. Wacker and Snodgrass (1960) have drawn attention to a raised serum lactic dehydrogenase in the presence of normal serum glutamic oxaloacetic transaminase as being of diagnostic value in pulmonary embolism. The respiratory studies with regard to the low pulmonary diffusing capacity are in keeping with the findings of Sasahara et al. (1964) in four patients with pulmonary embolic disease.

Characteristic of many published reports of thrombotic disease on oral contraceptives has been a relatively serious clinical picture. Eleven fatal cases were noted at the time of the 1962 Chicago Conference. Subsequently two of the six cases described by Schatz et al. (1965) had major pulmonary emboli and a third case required amputation of a limb for arterial thrombosis. A fatal case of superior mesenteric artery thrombosis was recorded by Reed and Coon (1963). In the case reported by Cohen and Sajid (1964) death was due to massive pulmonary thromboembolism. Hartveit (1965) has described the case of a 32-year-old woman who died with coronary thrombosis while on Anovlar.

\section{Summary}

Three healthy women developed intravascular thrombosis while receiving oral contraceptive therapy. Case 1 was fatal and directs attention to the possibility that arterial thrombosis may also exist in addition to the more common thrombophlebitis of the legs and pulmonary embolism.

We would like to express our gratitude to many people who have helped us with these cases: to Professor G. M. Bull for his permission to publish Case 1 ; to Dr. P. Balmer and Dr. J. Willis for the necropsy report and post-mortem studies; and to Dr. E. $\mathbf{M}$. McIlrath for the pulmonary angiogram investigations.

REFERENCES

Baines, G. F. (1965). Brit. med. 7., 1, 189.

Brakman, P., and Astrup, T. (1964). Lancet, 2, 10.

Brit. med. F., 1962, 2, 315.

Chicago Conference (1962). Conference on Thrombo-embolic Phenomena in Women. Searle.

Cohen, M. G., and Saiid, M. H. (1964). Delaware med. 7., 36, 81.

Egeberg, O., and Owren, P. A. (1963). Brit. med. F., 1, 220.

Food and Drugs Administration (1963). Final report on enavid by the ad hoc committee for the evaluation of a possible etiologic relaad hoc committee for the evaluation

Gaylis, H., and Kramer, M. V. (1962). S. Afr. med. F., 36, 1080.

Gaylis, H., and Kramer, M. V. (1962). S. Afr. med. 7., 36, 1080. Surg. Gynec. Obstet., 110, 327.

Hartveit, F. (1965). Brit. med. F., 1, 60.

Humphrey, J. G., and Newton, T., H. (1960). Brain, 83, 565.

Hutchinson, E. C., and Yates, P. O. (1960). Postgrad. med. F., 36, 14.

Johnson, H. C., and Walker, A. E. (1951). F. Neurosurg., 8, 631 .

Jordan, W. M.'(1961). Lancet, 2, 1146.

7. Amer. med. Ass., 1963, 185, 131 .

Leather, H. M. (1965). Lancet, 1, 270.

Lemmen, L. J., Davis, J. S., and Radnor, L. L. (1958). F. Neurosurg., $15,438$.

Lorentz, I. T. (1962). Brit. med. f., 2, 1191.

McIntyre, N., Phillips, M. J., and Voigt, J. C. (1962). Ibid., 2, 1029. MCWilliam, R. S., MacDonald, A. J., and Lindsay, I. (1963). 'Canad. med. Ass. 7., 88, 1032.

Mills, W. G. (1964). Proc. roy. Soc. Med., 57, 207.

Minogue, W. F., Halperin, I. C., Soler-Bechara, J., Varriale, P., and Flood, F. B.' (1963). New Engl. F. Med., 268, 1037.

Morrell, M. T., Truelove, S. C., and Barr, A. (1963). Brit. med. 7., 2, 830.

Phillips, L. L., Turksoy, R. N., and Southam, A. L. (1961). Amer. J. Obstet. Gynec., 82, 1216.

Reed, D. L., and Coon, W. W. (1963). New Engl. F. Med., 269, 622.

Richman, G. (1962). Brit. med. f., 2, 729

Sasahara, A. A., Stein, M., Simon, M., and Littmann, D. (1964). New Engl. $尹$. Med., 270, 1075 .

Schatz, I. J., Smith, R. F., Breneman, G. M., and Bower, G. C. (1964). 7. Amer. med. Ass., 188, 493.

Sobrero, A. J., Fenichel, R. L., and Singher, H. O. (1963). Ibid., 185, 136.

Staddon, I. S. (1962). Brit. med. f., 2, 857.

Stevens, A. E. (1961). Lancet, 2, 1005.

Stewart-Wallace, A. M. (1964). Brit. med. F., 2, 1528.

Wacker, W. E. C., and Snodgrass, P. J. (1960). F. Amer. med. Ass., 174, 2142 .

Williams, J. R., Wilcox, W. C., Andrews, G. J., and Burns, R. R. (1963). Ibid., 184, 473.

Zilkha, K. J. (1964). Brit. med. F., 2, 1132.

\title{
Aftercare of Artificially Paced Patients
}

\author{
RODNEY BLUESTONE,* M.B., M.R.C.P., D.oBST.R.C.o.G. ; ALAN HARRIS,* B.SC., M.B., M.R.C.P. ; \\ GEOFFREY DAVIES*
}

Brit. med. F., 1965, 1, 1589-1592

During the past four years 96 patients have been treated at this hospital with permanent pacemakers (Harris et al., 1965). They have needed careful supervision to ensure continuation of satisfactory pacing, and to study and deal with complications.

The technical problems entailed (Davies and Sowton, 1964) have resulted in the setting up of a special weekly follow-up clinic, to which most of these patients return at regular intervals. For many patients artificial pacing has been lifesaving and has enabled them to return to a normal existence, but it can be maintained only by specialized aftercare techniques (Davies and Sowton, 1964 ; Sowton and Davies, 1964), our personal experience of which we describe below in some detail.

\section{Pacemaker Systems in Use}

Epicardial Electrodes, Attached to an Implanted Abdominal Pacemaker.-Most patients with this system have two electrodes

* From St. George's Hospital, London. attached to their heart, one of which is spare and the other connected by a stainless-steel wire to a pacemaker unit implanted in the rectus sheath. Their platinum indifferent electrode is implanted in the subcutaneous tissue near the unit.

Epicardial Electrodes, Attached to an External Pacemaker.The electrode wires emerge from the abdominal subcutaneous tissue to connect with a small unit worn externally.

Endocardial fugular Catheter, Attached to an Implanted Pacemaker (Siddons and Davies, 1963).- These patients are paced by means of a solid electrode catheter passed via an external, occasionally internal, jugular vein and wedged at the apex of the right ventricle. The proximal end of the catheter has been fixed in the neck, then drawn down behind the clavicle to the axilla, where it is connected to an implanted unit. The indifferent electrode lies in the subcutaneous tissues of the axilla, adjacent to the unit.

Endocardial fugular Catheter, Attached to an External Unit. -The electrode catheter is positioned as above, but emerges from the neck vein to connect with a small unit. The indifferent 